\title{
A Case of Major Depression with Burning Mouth Syndrome and Tinnitus Successfully Treated with Vortioxetine
}

\section{Reiji Yoshimura \\ Atsuko Ikenouchi (D) \\ Naomichi Okamoto \\ Yuki Konishi}

Department of Psychiatry, University of Occupational and Environmental Health, Kitakyushu, Fukuoka, 8078555, Japan
Correspondence: Reiji Yoshimura Department of Psychiatry, University of Occupational and Environmental Health, Kitakyushu, Fukuoka, 8078555, Japan

Tel +81936927153

Fax +81935924894

Email yoshi621@med.uoeh-u.ac.jp

\begin{abstract}
We reported a case involving a patient diagnosed with major depression with associated burning mouth syndrome (BMS) and tinnitus who was successfully treated with vortioxetine. The case was 57-year-old Japanese woman diagnosed with major depression according to DSM-5. She experienced increased levels of stress when performing daily duties. Her dominant symptoms were depressive mood, anxiety, restlessness, insomnia, loss of appetite, difficulty of concentration, general fatigue, BMS, and tinnitus. She complained of pain as well as tongue and oral mucosa discomfort. She also experienced tinnitus, which she described as sounding like the buzz of cicadas. To treat symptoms, $20 \mathrm{mg} /$ day duloxetine was initially administered, which was gradually increased to $40 \mathrm{mg} /$ day. Depressive mood, restlessness, loss of appetite, and general fatigue were moderately ameliorated with treatment; however, symptoms such as anxiety, insomnia, and loss of concentration persisted. Vortioxetine $(10 \mathrm{mg} /$ day) was added to duloxetine and clonazepam therapy. Within 2 weeks, duloxetine and clonazepam treatments were gradually tapered, and the dosage of vortioxetine prescribed was increased to $20 \mathrm{mg}$ /day. Her BMS completely disappeared, and her glossodynia relieved.
\end{abstract}

Keywords: major depression, burning month syndrome, tinnitus, vortioxetine

\section{Introduction}

Burning mouth syndrome (BMS) is characterized by pain, burning, and/or dysesthesia of the tongue and oral mucosa, without pathological changes. For example, glossodynia may present as a burning or stinging sensation in the mouth that is associated with a normal mucosa in the absence of local or systemic disease such as burning mouth syndrome or oral dysesthesia. Glossodynia often occurs in middleaged or old-aged women who live alone ${ }^{1-3}$ and is sometimes associated with major depression or anxiety disorders. ${ }^{4,5}$ Here, we present a case involving a patient diagnosed with major depression with associated glossodynia and tinnitus who was successfully treated with vortioxetine. To the best of our knowledge, this is the first report to show that vortioxetine improves depressive symptoms associated with BMS and tinnitus.

\section{Case Report}

We report the case of a 57-year-old Japanese woman diagnosed with major depression according to DSM-5 criteria. ${ }^{6}$ The patient was referred to a local dental clinic 
and was diagnosed with BMS after she was examined by a dentist, who took the depressive state of the patient into account. Subsequently, the patient was referred to the outpatient unit of the psychiatry department of the university hospital.

The patient revealed that after she was transferred to a different department of the company at which she was employed, her workload increased and relationships with other workers became increasingly complicated. Thus, she experienced increased levels of stress when performing daily duties. Her dominant symptoms were depressive mood, anxiety, restlessness, insomnia, loss of appetite, difficulty of concentration, general fatigue, glossodynia, and tinnitus. She complained of pain as well as tongue and oral mucosa discomfort. She also experienced tinnitus, which she described as sounding like the buzz of cicadas.

Her vital signs were normal, with a blood pressure of $122 / 84 \mathrm{mmHg}$ and a heart rate of 69 beats/minute. Further, routine blood count, liver and renal function tests were normal. Thyroid-stimulating hormone, free $\mathrm{T} 4$, and thyroglobulin antibody tests were also normal. Additionally, her serum iron, zinc, and vitamin B12 levels were normal. No ear problems were revealed after examination by an otolaryngologist. Her Hamilton Rating Scale Depression (HAMD) ${ }^{7}$ score was 28 points.

To treat symptoms, $20 \mathrm{mg}$ /day duloxetine was initially administered, which was gradually increased to $40 \mathrm{mg} /$ day, because duloxetine has good evidence of efficacy in acute, adult MDD, and that duloxetine is an effective antidepressant in comparison with placebo, and similarly effective as various SSRIs has been confirmed. ${ }^{8}$ Depressive mood, restlessness, loss of appetite, and general fatigue were moderately ameliorated with treatment; however, symptoms such as anxiety, insomnia, and loss of concentration persisted. Her HAMD scores were 22 points lower when measured 8 weeks after duloxetine treatment was initiated. Her glossodynia was not relieved after treatment with duloxetine. Clonazepam ( $1 \mathrm{mg}$ /day) was added to ongoing duloxetine (40mg/day), but her glossodynia persisted. She experienced nausea when duloxetine was increased to $60 \mathrm{mg} / \mathrm{day}$. Thus, the antidepressant used was changed from duloxetine to vortioxetine. To make the change, vortioxetine $(10 \mathrm{mg} /$ day $)$ was added to duloxetine and clonazepam therapy. Within 2 weeks, duloxetine and clonazepam treatments were gradually tapered, and the dosage of vortioxetine prescribed was increased to $20 \mathrm{mg} /$ day.
Four weeks after initiation of vortioxetine treatment, the patient's depressive symptoms, including anxiety, loss of concentration, and insomnia, further improved. Her HAMD score was 12 points. Eight weeks post initiation of vortioxetine treatment, her glossodynia and tinnitus had partially improved. The patient did not experience tongue and oral mucosa pain but did feel mild oral mucosa discomfort. The frequency at which she experienced tinnitus reduced 10 weeks after she began treatment with vortioxetine, and her HAMD score was 7 points. She continued treatment with vortioxetine $(20 \mathrm{mg} /$ day $)$ and experienced relief of depressive symptoms. Her tinnitus completely disappeared. On rare occasions, she continued to complain of oral mucosa discomfort after experiencing workplace stress. The research protocol was approved by the Ethics Committee of the University of Occupational and Environmental Health, who waived the need for approval for publishing. Written informed consent was obtained from the patient for publication of this case report.

\section{Discussion}

BMS and tinnitus are sometimes accompanied by major depression. Antidepressants, including selective serotonin reuptake inhibitors, serotonin noradrenaline reuptake inhibitors, tricyclic antidepressants, benzodiazepines, and antipsychotic drugs, including olanzapine, are effective for the treatment of BMS., 910 Tinnitus is also treated with antidepressants. The efficacy of antidepressants for the treatment of tinnitus has not been fully validated. ${ }^{11}$ Adamo et $\mathrm{al}^{12}$ performed a longitudinal, single-assessment, open-label pilot study to evaluate the efficacy of vortioxetine for BMS, which is similar to glossodynia. Treatment with vortioxetine improved HAMD and visual analogue scale scores. Based on their findings, the authors concluded that vortioxetine was effective for the treatment of burning mouth syndrome and was well tolerated by patients.

The pathophysiology of BMS is complicated and not been fully elucidated, potential multiple mechanisms hypothesized, and numerous different phenotypes exist in BMS, ${ }^{13}$ although it likely involves neural pathways at different levels of the neuraxis. ${ }^{14}$ Moreover, the mechanisms by which vortioxetine improves glossodynia and tinnitus remain unknown. Vortioxetine has a broad action profile involving both serotonin (5HT) transporter and several 5HT receptors, including $5 \mathrm{HT}_{3 \mathrm{~A}}, 5 \mathrm{HT}_{7}$, and $5 \mathrm{HT}_{1 \mathrm{D}}$ receptor antagonists, $5 \mathrm{HT}_{1 \mathrm{~B}}$ partial agonist, and $5 \mathrm{HT}_{1 \mathrm{~A}}$ agonist. ${ }^{15,16}$ This pharmacological profile of vortioxetine might be related to its efficacy. In conclusion, vortioxetine 
is an attractive candidate for the treatment of major depression associated with BMS and tinnitus. However, a single case lacks sufficient power to make such conclusion, because the possibility that BMS and tinnitus can remit on its own could not be ruled out. We should perform doubleblind placebo-controlled studies with vortioxetine for major depression with BMS and tinnitus to validate the findings of this case.

\section{Disclosure}

The authors report no conflicts of interest in this work.

\section{References}

1. Takenoshita M, Sato T, Kato Y, et al. Psychiatric diagnoses in patients with burning mouth syndrome and atypical odontalgia referred from psychiatric to dental facilities. Neuropsychiatr Dis Treat. 2010;6:699-705. doi:10.2147/NDT.S12605

2. Maier C. Vital disorders of the mouth (glossodynia) in depressive involutional psychoses. Nervenarzt. 1986;57(2):113-115.

3. Eli I, Baht R, Littner MM, Kleinhauz M. Detection of psychopathologic trends in glossodynia patients. Psychosom Med. 1994;56 (5):389-394. doi:10.1097/00006842-199409000-00002

4. Inamitsu T. Functional somatic syndrome in dental practice. Nihon Rinsho. 2009;67(9):1749-1754.

5. Davies SJ, Underhill HC, Abdel-Karim A, et al. Individual oral symptoms in burning mouth syndrome may be associated differentially with depression and anxiety. Acta Odontol Scand. 2016;74(2):155-160. doi:10.3109/00016357.2015.1100324
6. American Psychiatric Association. Diagnostic and Statistical Manual of Mental Disorders. 5th ed. Washington DC: American Psychiatric Association; 2013.

7. Hamilton M. Development of a rating scale for primary depressive illness. Br J Soc Clin Psychol. 1967;6:278-296. doi:10.1111/j.20448260.1967.tb00530.x

8. Girardi P, Pompili M, Innamorati M, et al. Duloxetine in acute major depression: review of comparisons to placebo and standard antidepressants using dissimilar methods. Hum Psychopharmacol. 2009;24 (3):177-190. doi:10.1002/hup.1005

9. Zakrzewska J, Buchanan JA. Burning mouth syndrome. BMJ Clin Evid. 2016;2016:1301.

10. Ueda N, Kodama Y, Hori $\mathrm{H}$, et al. Two cases of burning mouth syndrome treated with olanzapine. Psychiatry Clin Neurosci. 2008;62(3):359-361. doi:10.1111/j.1440-1819.2008.01806.x

11. Baldo P, Doree C, Molin P, McFerran D, Cecco S, Antidepressants for patients with tinnitus. Cochrane Database Syst Rev. 2012;9: CD003853. doi:10.1002/14651858.CD003853.pub3

12. Adamo D, Pecoraro G, Aria M, Favia G, Mignogna MD. Vortioxetine in the treatment of mood disorders associated with burning mouth syndrome: results of an open-label, flexible-dose pilot study. Pain Med. 2020;21(1):185-194. doi:10.1093/pm/pnz120

13. Teruel A, Patel S. Burning mouth syndrome: a review of etiology, diagnosis, and management. Gen Dent. 2019;67(2):24-29.

14. Gurvits GE, Tan A. Burning mouth syndrome. World J Gastroenterol. 2013;19(5):665-672. doi:10.3748/wjg.v19.i5.665

15. Sowa-Kućma M, Pańczyszyn-Trzewik P, Misztak P, et al. Vortioxetine: a review of the pharmacology and clinical profile of the novel antidepressant. Pharmacol Rep. 2017;69:595-601. doi:10.1016/j.pharep.2017.01.030

16. Alvarez E, Perez V, Artigas F. Pharmacology and clinical potential of vortioxetine in the treatment of major depressive disorder. Neuropsychiatr Dis Treat. 2014;10:1297-1307. doi:10.2147/NDT. S41387

\section{Publish your work in this journal}

The International Medical Case Reports Journal is an international, peer-reviewed open-access journal publishing original case reports from all medical specialties. Previously unpublished medical posters are also accepted relating to any area of clinical or preclinical science. Submissions should not normally exceed 2,000 words or 4 published pages including figures, diagrams and references. The manuscript management system is completely online and includes a very quick and fair peer-review system, which is all easy to use. Visit http://www.dovepress.com/testimonials.php to read real quotes from published authors. 